\title{
Influence of involuntary automated motor activity upon voluntary attention and memory
}

\author{
Eugene Brunner*, and Denis Mokrentsov \\ V. I. Vernadsky Crimean Federal University, Russia
}

\begin{abstract}
The article deals with the changes and interaction of different attention and memory parameters under the influence of involuntary (automated) motor activity. Methodology. To simulate automated motor activity, we used chewing gum. To study attention, we used proofreading. We also tested short-term, long-term and working memory. 66 people at the age from 17 to 24 took part in the research. Conclusions. The conclusion is that automatic motor activity leads to considerable increase of attention and memory. This is expressed in the significant increase in the values of just about all the studied parameters, the change in the structure and strength of correlation relationships, and also (according to the cluster analysis) in the restructuring of the hierarchy of the information processing. The possible mechanisms of the phenomena under observation are discussed.
\end{abstract}

\section{Introduction}

Nowadays there exist a great number of publications dedicated to the study of attention and memory. However, very few of them underline the connection of these cognitive processes with movement.

The connection between attention and movement was mentioned as far back as by Th. Ribot within the framework of his motor theory of attention and imagination [1, p. 19]. I. Pavlov, considering the simplest forms of attention, pointed out that it is closely connected with the orienting reflex [2]. Nowadays scientists [3, p. 216-217; 4; 5] report that attention is manifested in different behavioral complexes in the form of macro- and micro movements of the body and limbs, certain postures, changes in facial expressions, direction of gaze to the external or internal object of attention.

There also exist experimental data of improving executive vigilance after exercise at moderate intensity, as well as of faster overall reaction time without impairing error rates [6].

Attention is closely related to other components of the cognitive sphere as well. It should be noted that it can affect both the cognitive sphere in general and individual cognitions in particular. The inseparable connection between attention and memory was pointed out in the studies by R. Desimone and I. Duncan [7], A. Ivanitsky et al. [8], R. Naatanen [9], M. Slavutskaya [10], E. Sokolov [11], N. Suvorov, O. Tairov [12], G. Mangun, A. Jha, J. Hopfinger, T. Handy [13], M. Posner [14; 15]. It has been

\footnotetext{
*brunner eu@mail.ru
} 
established that this connection is manifested in the direct influence of attention upon the speed, accuracy, retention and the duration of retention of memorized material (B. Ananiev [16], N. Dobrynin [17], N. Nevelsky [18], A. Nechaev [19], N. Serkova [20]). At the same time, the formation of engrams is influenced not only by the voluntary or involuntary nature of memorization, the degree of interest, emotional attitude to information, its content and form, as well as the state of health and the degree of fatigue, but also by the direction and duration of attention [21, p. 195].

The connection between attention and thinking also exists beyond any doubt. The famous Russian physiologist I. Pavlov wrote about it as follows: "... the main rule of thinking is to focus on a certain point" [22]. The influence of attention on mental activity was also pointed out by such scientists as B. Ananiev [23, p. 230], Th. Ribot [1], G. Whipple [24], R. Frankin [25, p. 39], S. Spearman [26, p. 259-269] and others.

The close interrelation between perception and attention was described by such scientists as B. Ananiev [16], F. Gonobolin [27], L. Grigorieva [28; 29], N. Lange [30], I. Moskalik [31], I. Sechenov [32] and others.

In spite of the fact that cognitive issues have high extent of prior scientific development, we failed to find experimental studies indicating that conscious or automated motor acts can lead to attention and memory changes. We also failed to find studies aimed at peculiarities of connection between attention and memory during motor activity.

In this regard, the aim of this work is to study influence of automated (involuntary) motor activity upon voluntary attention and auditory memory.

\section{Methods}

To simulate the process of involuntary automated motor activity, we used mastication of chewing gum (two «Orbit XXL» gum pellets with mass total of $2.7 \mathrm{~g}$ ). This choice was made, because chewing is a habitual action, it can be performed automatically and, as a result, the testee has no need in making additional efforts, while carrying out other activities.

To study attention, we used the proofreading test based on E. Landolt's rings. Earlier we have described in detail the method of processing attention parameters [33-35]. The duration of the work with the formsheet was five minutes.

The study of auditory short-term and long-term memory for words was carried out using A. Luria's methodology "10 words memorizing", and auditory short-term memory for numbers - using a digit span test by Jacobs. In order to test the working memory number span, the testees were aurally presented with 10 rows of five numbers each, which they had to memorize, then add up in mind in successive order, and finally write down the result [34].

Differences between the parameters under consideration were assessed with the Student's paired sample t-test. Differences between means were deemed significant when the corresponding two-sided P-value was below .05. Correlation analysis was performed using Spearman's test. All statistical analyses were conducted using Statistica for Windows (ver. 8.0).

\section{Results}

The study involved 66 testees (27 male, 39 female) at the age of 17-24 (19.35 \pm 2.01$)$.

The means of attention and memory parameters, without and during automated motor activity, as well as their variation range and the reliability of changes are presented in table 1 
Table 1. Mean values of attention and memory parameters and the reliability of their changes in 66 testees without and during automated motor activity.

\begin{tabular}{|c|c|c|c|c|c|c|}
\hline \multirow{2}{*}{\multicolumn{2}{|c|}{ Parameter }} & \multicolumn{2}{|c|}{ Without } & \multicolumn{2}{|c|}{ During } & \multirow[b]{2}{*}{$\begin{array}{l}\text { Reliability } \\
\text { (Student's } \\
\text { t-test; } P<\text { ) }\end{array}$} \\
\hline & & $\begin{array}{c}\text { Mean } \pm \\
\text { Std. } \\
\text { dev. }\end{array}$ & $\begin{array}{l}\operatorname{Min} / \\
\operatorname{Max}\end{array}$ & $\begin{array}{c}\text { Mean } \pm \\
\text { Std. } \\
\text { dev. }\end{array}$ & $\begin{array}{l}\operatorname{Min} / \\
\operatorname{Max}\end{array}$ & \\
\hline \multicolumn{7}{|c|}{ Attention } \\
\hline$A$ & Productivity (signs per sec) & $\begin{array}{c}11,2 \pm \\
3,1\end{array}$ & $\begin{array}{l}5,2 / \\
21,3 \\
\end{array}$ & $\begin{array}{c}12,8 \pm \\
3,19\end{array}$ & $\begin{array}{l}5,3 / \\
20,1 \\
\end{array}$ & $\begin{array}{c}-4,54 \\
0,000025\end{array}$ \\
\hline$T_{2}$ & $\begin{array}{l}\text { Accuracy (conventional } \\
\text { units) }\end{array}$ & $\begin{array}{c}8,9 \pm \\
0,9\end{array}$ & $\begin{array}{l}6,2 / \\
10,0\end{array}$ & $\begin{array}{c}9,4 \pm \\
0,5\end{array}$ & $\begin{array}{l}7,5 / \\
10,0\end{array}$ & $\begin{array}{c}-4,31 \\
0,000057\end{array}$ \\
\hline $\boldsymbol{E}_{2}$ & Thinking productivity (signs) & $\begin{array}{c}295,9 \pm \\
76,9 \\
\end{array}$ & $\begin{array}{l}116,5 / \\
510,5\end{array}$ & $\begin{array}{c}360,6 \pm \\
96,2\end{array}$ & $\begin{array}{l}142,9 / \\
579,8\end{array}$ & $\begin{array}{c}-6,00 \\
0,000000\end{array}$ \\
\hline $\boldsymbol{K}$ & Attention concentration $(\%)$ & $\begin{array}{c}753,1 \pm \\
199,2\end{array}$ & $\begin{array}{c}137,6 / \\
1000\end{array}$ & $\begin{array}{c}846,7 \pm \\
135,9\end{array}$ & $\begin{array}{c}327,4 / \\
1000\end{array}$ & $\begin{array}{c}-3,70 \\
0,000445\end{array}$ \\
\hline $\boldsymbol{V}$ & $\begin{array}{l}\text { Volume of visual information } \\
\text { (bits) }\end{array}$ & $\begin{array}{c}199,4 \pm \\
55,1 \\
\end{array}$ & $\begin{array}{l}92,0 / \\
379,3 \\
\end{array}$ & $\begin{array}{c}228,7 \pm \\
56,7 \\
\end{array}$ & $\begin{array}{l}94,9 / \\
357,4 \\
\end{array}$ & $\begin{array}{c}-4,54 \\
0,000025\end{array}$ \\
\hline$Q$ & $\begin{array}{l}\text { Information processing speed } \\
\text { (bits per sec) }\end{array}$ & $\begin{array}{c}5,0 \pm \\
1,7\end{array}$ & $\begin{array}{l}1,6 / \\
9,5\end{array}$ & $\begin{array}{c}6,53 \pm \\
2,1\end{array}$ & $\begin{array}{l}1,7 / \\
10,9\end{array}$ & $\begin{array}{c}-5,54 \\
0,000001\end{array}$ \\
\hline$A_{y p}$ & $\begin{array}{l}\text { Intellectual work capacity } \\
\text { (signs per sec) }\end{array}$ & $\begin{array}{c}8,5 \pm \\
2,9\end{array}$ & $\begin{array}{l}2,6 / \\
16,3\end{array}$ & $\begin{array}{c}11,2 \pm \\
3,4\end{array}$ & $\begin{array}{l}4,2 / \\
18,6\end{array}$ & $\begin{array}{c}-6,19 ; \\
0,000000\end{array}$ \\
\hline $\boldsymbol{R}$ & Efficiency of work (\%) & $\begin{array}{c}949,6 \pm \\
39,3 \\
\end{array}$ & $\begin{array}{c}810,4 / \\
1000\end{array}$ & $\begin{array}{c}968,6 \pm \\
26,8 \\
\end{array}$ & $\begin{array}{c}857,7 / \\
1000\end{array}$ & $\begin{array}{c}-3,85 \\
0,000275\end{array}$ \\
\hline \multicolumn{7}{|c|}{ Memory } \\
\hline$\frac{3}{\Sigma^{\prime}}$ & short-term memory for words & $\begin{array}{l}5,7 \pm \\
1,42\end{array}$ & $\begin{array}{l}3,0 / \\
9,0\end{array}$ & $\begin{array}{c}6,2 \pm \\
1,7\end{array}$ & $\begin{array}{l}3,0 / \\
10,0\end{array}$ & - \\
\hline $\begin{array}{l}z^{\prime} \\
z^{\prime}\end{array}$ & long-term memory for words & $\begin{array}{c}8,4 \pm \\
1,6\end{array}$ & $\begin{array}{l}3,0 / \\
10,0\end{array}$ & $\begin{array}{c}9,6 \pm \\
1,0\end{array}$ & $\begin{array}{l}6,0 / \\
10,0\end{array}$ & $\begin{array}{c}-3,08 \\
0,005934\end{array}$ \\
\hline $\begin{array}{l}z \\
z_{1} \\
\vdots\end{array}$ & working memory for figures & $\begin{array}{l}32,5 \pm \\
5,3\end{array}$ & $\begin{array}{l}20,0 / \\
40,0\end{array}$ & $\begin{array}{c}31,57 \pm \\
6,96\end{array}$ & $\begin{array}{l}17,0 / \\
40,0\end{array}$ & - \\
\hline $\begin{array}{l}z_{1} \\
z_{5}^{\prime}\end{array}$ & $\begin{array}{l}\text { short-term memory for } \\
\text { figures }\end{array}$ & $\begin{array}{c}6,82 \pm \\
0,96\end{array}$ & $\begin{array}{l}4,75 / \\
10,0\end{array}$ & $\begin{array}{c}7,19 \pm \\
1,14\end{array}$ & $\begin{array}{l}5,0 / \\
9,75\end{array}$ & $\begin{array}{c}-2,87 \\
0,009454\end{array}$ \\
\hline
\end{tabular}

In Fig. 1-2 there are histograms, which clearly show the difference in the means (in percent) of attention and memory parameters during automated unconscious motor activity as compared to the control series. 


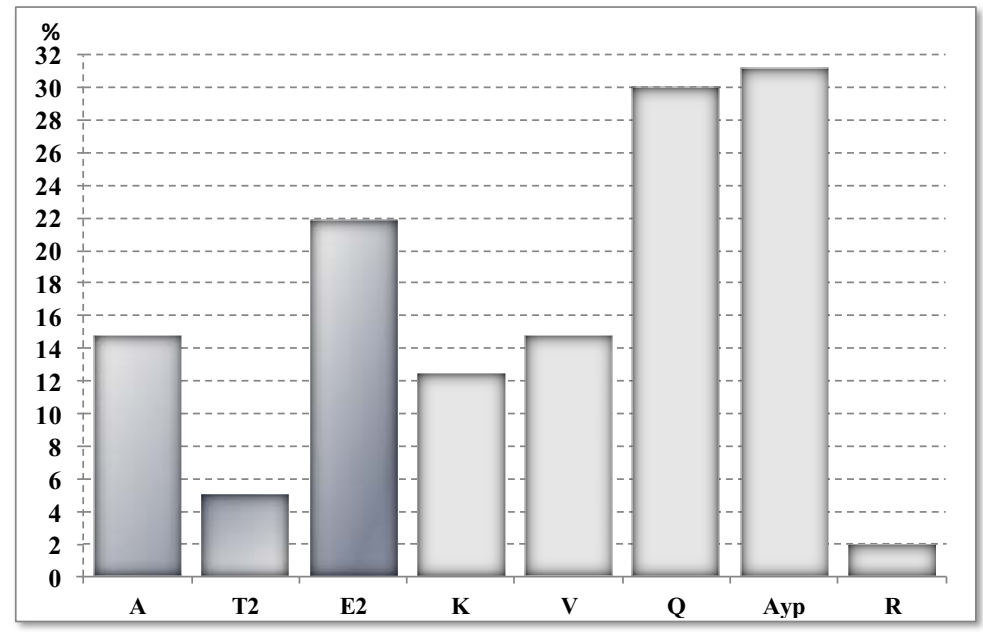

Fig. 1. Histogram of changes in mean values of attention parameters in the process of automated motor activity as compared to the control series. Note. The abscissa shows attention parameters, and the ordinate shows the difference in means in percent. The decoding of the letter designations is given in table 1 .

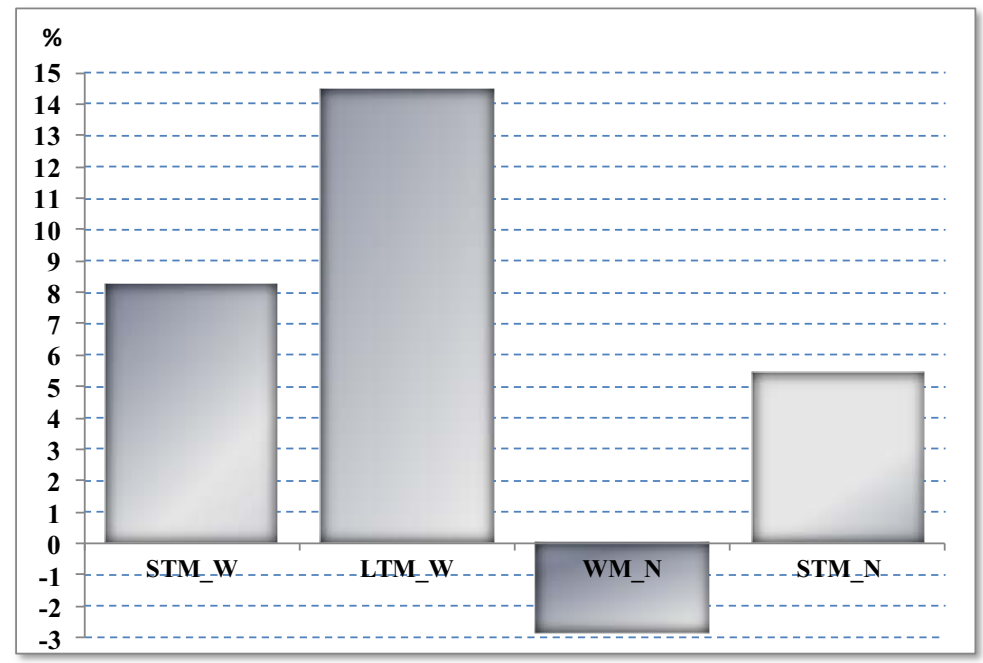

Fig. 2. Histogram of changes in the mean values of memory parameters in the process of automated motor activity as compared to the control series. Note. Along the abscissa - memory parameters, on the ordinate - the difference in means in percent. The decoding of the letter designations is given in table 1.

Analysis of the changes observed (Table 1. and Fig. 1-2) shows that automated motor activity leads to a significant increase in the mean values of all the considered attention parameters, as well as the volume of long-term memory for words $(\boldsymbol{L T M} \boldsymbol{W})$ and the volume of short-term memory for numbers $(\boldsymbol{S T M} \boldsymbol{N})$. At the same time, the largest increase in mean values occurs in such parameters as $\boldsymbol{A y \boldsymbol { p }}$ (by 31.18\%), $\boldsymbol{Q}$ (by $30.0 \%$ ) and $\boldsymbol{E}_{2}$ (by $21.85 \%$ ). There is also a noticeable tendency towards a decrease (by $2.86 \%$ ) in the volume of working memory ( $\left.\boldsymbol{W M} \_\boldsymbol{N}\right)$. 
To understand how and in what way the relationship between the considered parameters changed in the course of unconscious motor activity, we performed correlation and cluster analyzes.

Correlation analysis data are presented in Table 2.

Table 2. Matrix of changes in correlation relationships between parameters of voluntary attention and memory before and during automated motor activity.

\begin{tabular}{|c|c|c|c|c|c|c|c|c|c|c|c|c|}
\hline \multirow[b]{3}{*}{ 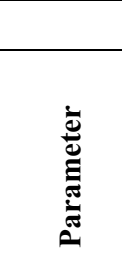 } & \multicolumn{12}{|c|}{ Without automated motor activity } \\
\hline & \multicolumn{8}{|c|}{ Attention } & \multicolumn{4}{|c|}{ Memory } \\
\hline & $A$ & $T_{2}$ & $\boldsymbol{E}_{2}$ & $\boldsymbol{K}$ & $\boldsymbol{V}$ & $Q$ & $A_{y p}$ & $\boldsymbol{R}$ & $\underset{\infty}{\stackrel{1}{\mid}}$ & $\underset{z}{\mathbf{z}}$ & $\begin{array}{l}z_{1} \\
z^{\prime} \\
\vdots\end{array}$ & $\sum_{5}^{z}$ \\
\hline $\boldsymbol{A}$ & & -.02 & $.91 !$ & -.02 & $1,0 !$ & $.63 !$ & $.58 !$ & .03 & .00 & -.02 & .04 & .22 \\
\hline$T_{2}$ & .12 & & $.33 !$ & $.94 !$ & -.02 & $.62 !$ & $.72 !$ & $.88 !$ & .20 & .14 & .04 & .11 \\
\hline $\boldsymbol{E}_{2}$ & $.96 !$ & $.33 !$ & & $.32 !$ & $.91 !$ & $.84 !$ & $.84 !$ & $.36 *$ & .07 & .01 & .08 & $.27 *$ \\
\hline$K$ & .16 & $.84 !$ & $.35 !$ & & -.03 & $.65 !$ & $.70 !$ & $.94 !$ & .21 & .17 & .01 & .16 \\
\hline$V$ & $1,0 !$ & .12 & $.97 !$ & .16 & & $.63 !$ & $.58 !$ & .03 & .00 & -.02 & .04 & .22 \\
\hline$Q$ & $.88 !$ & $.38 !$ & $.93 !$ & $.51 !$ & $.88 !$ & & $.94 !$ & $.72 !$ & .13 & .01 & .05 & .19 \\
\hline$A_{y p}$ & $.86 !$ & $.53 !$ & $.95 !$ & $.51 !$ & $.86 !$ & $.93 !$ & & $.71 !$ & .19 & .03 & .12 & .21 \\
\hline$R$ & .21 & $.78 !$ & .37 & $.94 !$ & .21 & $.57 !$ & $.51 !$ & & .14 & .13 & -.06 & .11 \\
\hline$S T M \_W$ & -.09 & $.43 *$ & -.02 & $.32 *$ & -.09 & -.15 & .00 & .19 & & .13 & .14 & .09 \\
\hline LTM_W & .22 & .04 & .21 & .17 & .23 & .29 & .35 & .16 & .05 & & -.23 & -.11 \\
\hline$W M \_N$ & -.08 & .14 & -.09 & $.46^{*}$ & -.08 & .05 & -.12 & $.47 *$ & .08 & .00 & & $.45^{*}$ \\
\hline \multirow[t]{2}{*}{ STM_N } & .15 & -.31 & .06 & -.11 & .15 & .17 & .00 & .03 & $-.59 *$ & -.10 & .38 & \\
\hline & \multicolumn{12}{|c|}{ During automated motor activity } \\
\hline
\end{tabular}

Note. Sign "!" indicates the significant values of the correlation relationships, which occur both at the control stage of the research and during the automated motor activity. Sign "*" denotes significant values of correlation relationships, which are different in the control and experimental series. Areas of intersection of attention and memory parameters are highlighted in light gray. The decoding of the letter designations is given in table 1.

The results of the correlation analysis (Table 2) convincingly show that in the process of automated motor activity there is, firstly, a change in the strength of conjugation (with a leading tendency to increase) between the attention parameters and, secondly, their number changes insignificantly (significant correlation disappears between $\boldsymbol{R}$ and $\boldsymbol{E}_{2}$ ). As for the dynamics of the relationship between memory parameters, it can be seen that the significant relationship between the $\boldsymbol{S T M} \boldsymbol{N}$ and $\boldsymbol{W} \boldsymbol{M} \_\boldsymbol{N}$ parameters, which was revealed at the control stage of our research, disappears, and a significant relationship appears between the $\boldsymbol{S T M} \boldsymbol{N}$ and $\boldsymbol{S T M} \boldsymbol{W}$ parameters in the process of chewing gum mastication.

More essential changes occur in the structure of the relationship between attention and memory parameters. Thus, a significant relationship between the $\boldsymbol{E}_{2}$ and $\boldsymbol{S T M} \boldsymbol{M}_{-}$ parameters, revealed at the control stage of our research, disappears, but there appears one between the $\boldsymbol{T}_{\boldsymbol{2}}$ and $\boldsymbol{S T M} \boldsymbol{T}, \boldsymbol{K}$ and $\boldsymbol{S T} \boldsymbol{M}_{-} \boldsymbol{W}, \boldsymbol{K}$ and $\boldsymbol{W} \boldsymbol{M}_{-} \boldsymbol{N}, \boldsymbol{R}$ and $\boldsymbol{W} \boldsymbol{M}_{-} \boldsymbol{N}$ parameters correspondingly during unconscious involuntary motor activity.

It is noteworthy that between the majority of parameters there are predominantly significant positive values of the correlation coefficients, with the exception of the STM_N 
and $\boldsymbol{S T M} \boldsymbol{W}$ parameters, between which significant inversely proportional relationships (r $=-.59$ ) are revealed during involuntary mastication of chewing gum.

It is well known that correlation analysis only allows one to establish the presence of a relationship between parameters, but does not make it possible to determine the cause-andeffect relationships. In order to deal with this issue, we conducted a cluster analysis. Its results are shown in Fig. 3-4.

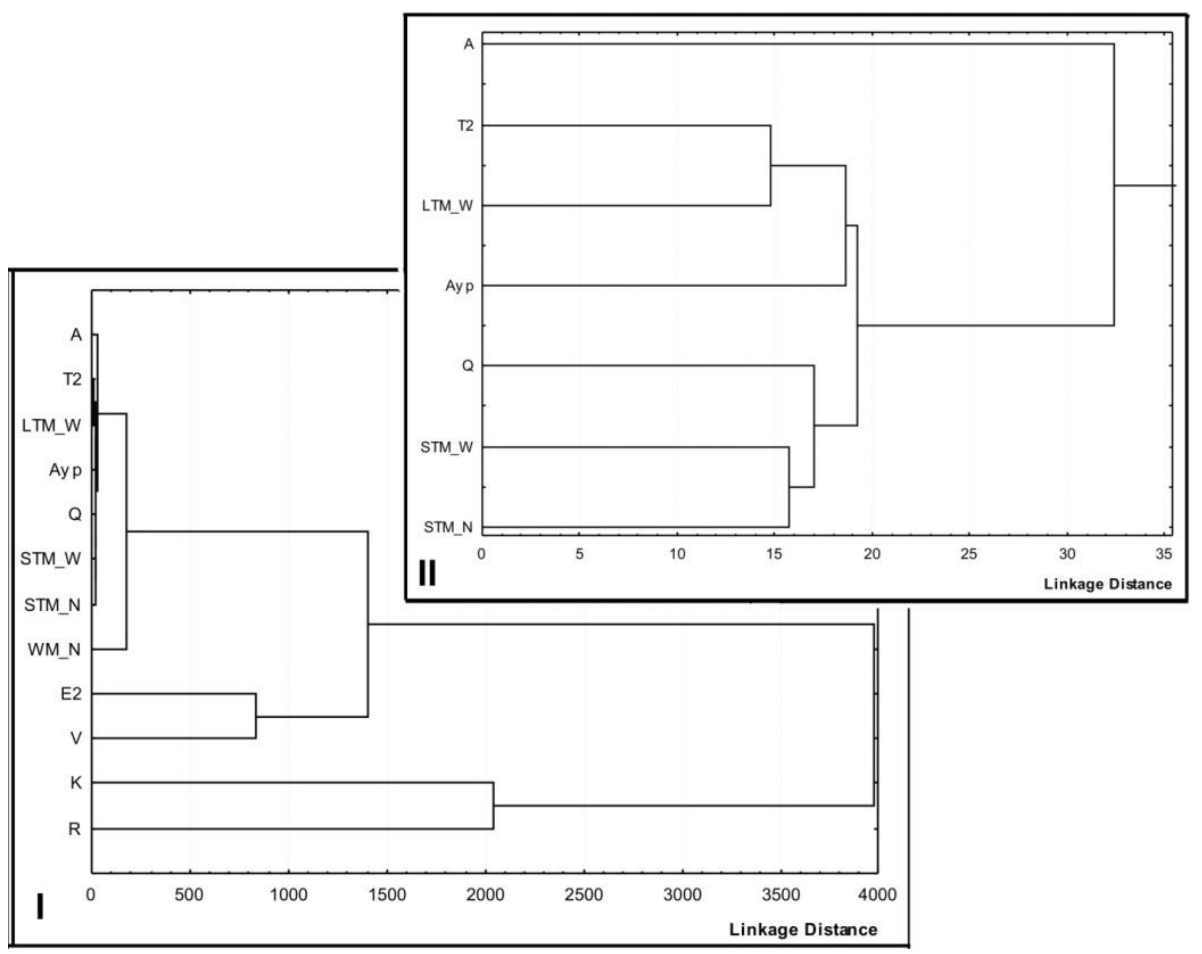

Fig. 3. Horizontal dendrogram of attention and memory parameters at the control stage of the research (I) and an enlarged fragment of the $\boldsymbol{A - S T M} \boldsymbol{N}$ area (II). Notes. The abscissa is the linkage distance (y.e), the ordinate is the parameters. The letter designations of the parameters are presented in table 1.

In the dendrogram obtained at the control stage of the research (Fig. 3.), six clusters can be distinguished. The first cluster includes such parameters as $\boldsymbol{S T M} \boldsymbol{W}_{-}, \boldsymbol{S T M} \boldsymbol{M}_{-} \boldsymbol{N}$ and $\boldsymbol{Q}$, the second one - $\boldsymbol{T}_{2}, \boldsymbol{L T} \boldsymbol{M}_{-} \boldsymbol{W}$ and $\boldsymbol{A y p}$, the third one - $\boldsymbol{A}$, the fourth one - $\boldsymbol{W} \boldsymbol{M} \_\boldsymbol{N}$, the fifth one $\boldsymbol{E}_{2}$ and $\boldsymbol{V}$ and the sixth cluster includes the parameters $\boldsymbol{K}$ and $\boldsymbol{R}$.

In the dendrogram based on the data of the series when the testees masticated chewing gum (Fig. 4), six clusters can also be distinguished. The first cluster includes such parameters as $\boldsymbol{S T M} \boldsymbol{W}, \boldsymbol{S T M} \boldsymbol{N}$ and $\boldsymbol{Q}$, the second one $-\boldsymbol{T}_{2}$ and $\boldsymbol{L T M} \boldsymbol{T} \boldsymbol{W}$, the third one $-\boldsymbol{A}$ and $\boldsymbol{A y p}$, the fourth one - $\boldsymbol{W} \bar{M}_{-} \boldsymbol{N}$, the fifth one $-\boldsymbol{E}_{2}$ and $\boldsymbol{V}$ and the sixth cluster includes the parameters $\boldsymbol{K}$ and $\boldsymbol{R}$. 


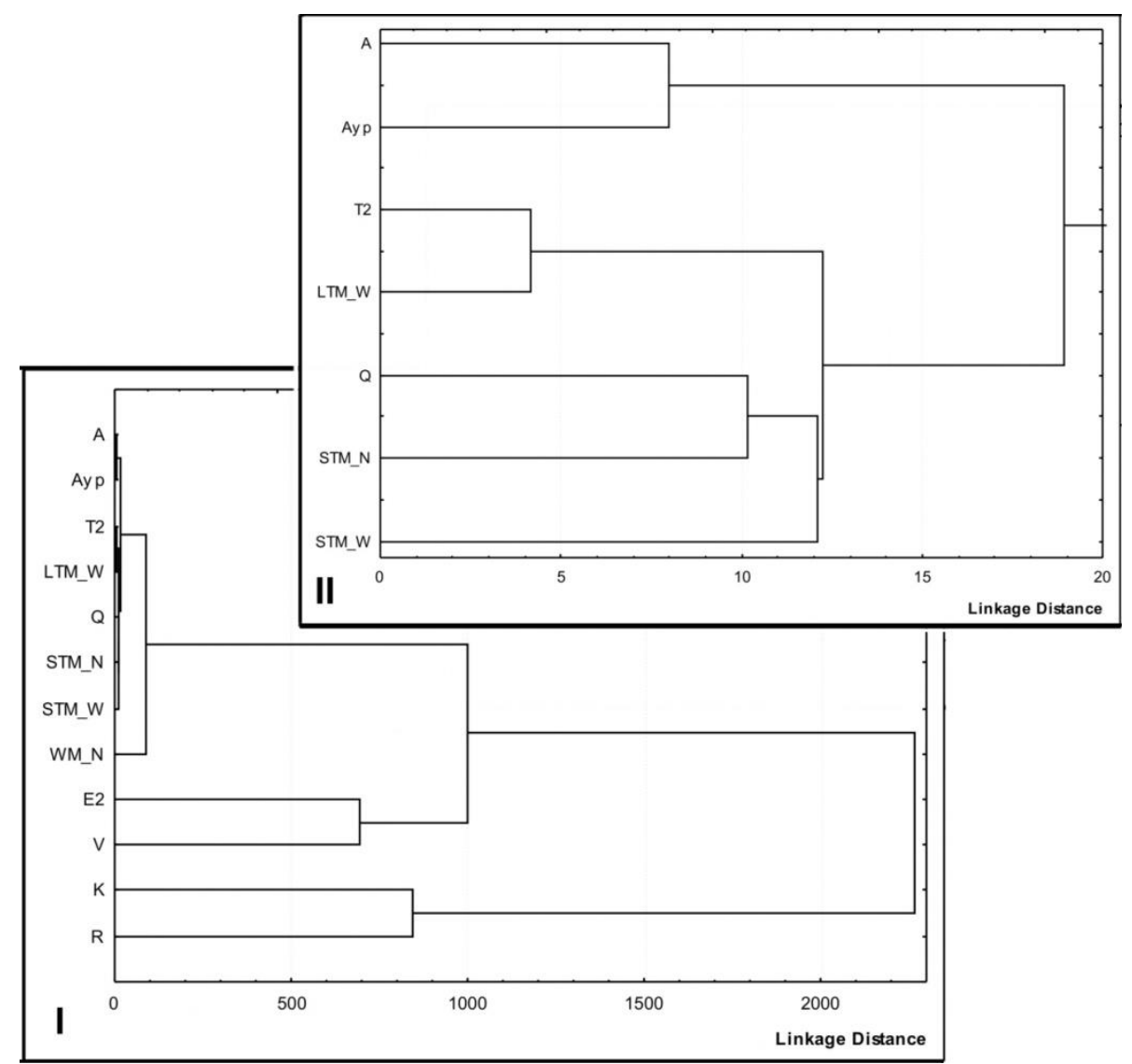

Fig. 4. Horizontal dendrogram of attention and memory parameters during physical activity (I), consisting in mastication of chewing gum and an enlarged fragment of the $\boldsymbol{A}-\boldsymbol{S T} \boldsymbol{M}_{-} \boldsymbol{W}$ area (II). Notes. Same as in Fig. 2.

Thus, we can conclude that unconscious involuntary motor activity leads to a certain change in the hierarchical structure of relationships between cognitive processes. As can be seen from the dendrograms (Fig. 3-4), this manifested itself in a change in the patterns of the second and third clusters.

\section{Discussion}

As a discussion of the results presented in this work, let us express the consideration dwelling upon the possible mechanisms of the observed processes.

Let us remind that to simulate physical activity, the testees had to masticate chewing gum. Consequently, the observed changes can be associated both with the actual motor act, leading to the activation of the motor parts of the brain, and with the irritation of the receptors in the oral cavity, that activate the brain parts associated with the digestive system. We see that quite powerful foci of excitation could arise in the brain, which, according to the study of A. Ukhtomsky about the dominant [36, p. 170], on the one hand, lead to inhibition of insignificant signals, and, on the other hand, form the physiological basis for the act of attention associated with the selectivity of the nervous system. Considering the fact that, in contrast to the motor system, the digestive system is predominantly represented in the lower and more ancient parts of the brain [37], we are 
nevertheless inclined to make an assumption that it is not the digestive system but the unconscious motor activity that influences the processes identified by us.

Thus, let us try to analyze the identified dynamics in a complex.

The correlation analysis has shown that most attention parameters have significant direct proportional relationships with each other. This means that the activation (or suppression) of even one of them will lead to the activation (or suppression) of all the other parameters as well. Thus, on the basis of a significant increase in the mean values of all the attention parameters examined, it can be concluded that unconscious motor activity leads to the attention activation in general.

We observe a somewhat different picture when analyzing memory parameters. As shown by the correlation analysis (Table 2), these parameters are weakly related to each other. This is probably due to the fact that in the brain the centers responsible for shortterm, long-term and working memory do not have such a close connection as the centers associated with attention. It is possible that the connection between these types of memory is formed only in need and appears (or disappears) in accordance with external conditions. This can explain the fact that in a situation where the testees did not masticate chewing gum, there was a significant positive relationship between the parameters of short-term $(\boldsymbol{S T M} \boldsymbol{N})$ and working $(\boldsymbol{W M} \boldsymbol{N})$ memory for numbers. When the external situation changed, the structure of correlations changed also: a significant relationship between the STM_N and $\boldsymbol{W M} \boldsymbol{M}_{-} \boldsymbol{N}$ parameters disappeared and a negative one appeared between the $\boldsymbol{S T M} \boldsymbol{N}$ and $\boldsymbol{S T M} \boldsymbol{W}$ parameters. The latter may indicate that the activation of short-term memory for numbers leads to the suppression of short-term memory for words, and vice versa. This, probably, can explain the fact that people with humanitarian mindset experience difficulties while operating the numbers, and people with mathematical mindset face difficulties when operating poorly structured text information.

No less interesting are the data on the dynamics of correlations between attention and memory parameters.

Under normal conditions, when there is no brain activation through automated motor activity, only one significant direct proportional relationship was revealed: between the attention parameter $\boldsymbol{E}_{2}$ and the memory parameter $\boldsymbol{S T M} \boldsymbol{N}$ (Table 2). Let us try to explain this relationship.

We should remind that firstly, the $\boldsymbol{E}_{2}$ indicator is determined by the working speed and the accuracy of the task fulfillment $[33 ; 35 ; 38]$. Essentially, mental productivity is the effort made by a person in order to maintain their focus while performing work in an environment that requires precision. We need such activity most often when working with clearly structured information: in our case, with numbers and with objects unusual for the testees (ophthalmologic rings). Secondly, according to the experiment conditions, in order to test working memory, the testees had to keep in mind five numbers and to add them successively, which also requires certain mental efforts and accuracy.

Thus, if we consider the work with the proofreading form sheet, the relationship between $\boldsymbol{E}_{2}$ and $\boldsymbol{S T M} \boldsymbol{N}$ can be explained as follows. According to the conditions of the experiment, when performing the attention task, the testees had to keep in their memory the information about which rings should be looked for and how they are to be crossed out. It is quite obvious that such information can only be stored in working memory. Considering that only people with humanitarian mindset took part in the study, and the work itself is associated with both accuracy and speed, we assume that for them operating ophthalmologic rings and numbers is most likely an operation of the same order, which explains the connection between mental productivity and working memory.

In its turn, the disappearance of a significant relationship between the $\boldsymbol{E}_{2}$ and $\boldsymbol{S T M} \boldsymbol{N}$ parameters during unconscious involuntary motor activity can be explained as follows. First, the testees performed the same operation with the same rings they had to work over at 
the control stage of the research. Consequently, in this case they had no need in making an effort to keep in their working memory the information about which rings to look for and how to delete them. Secondly, because of the activation of the motor cortex due to involuntary motor activity, a more powerful activation of attention and some memory parameters occurred, which is confirmed by a significant increase in their mean values. The result was a restructuring of the information processing mechanism. The latter is confirmed by the emergence of new significant correlation coefficients (Table 2) and a change in the hierarchical structure of relationships between cognitive processes, identified with the help of cluster analysis (Fig. 3-4).

Let us now discuss the possible mechanisms of interaction between attention and memory when working with a proofreading test. To do this, let us analyze the obtained dendrograms (Fig. 3-4).

As we mentioned above, changes in the restructuring of the dendrogram pattern during physical activity affected the second and third clusters. At the same time, as can be seen, these clusters are inextricably linked with the third and fourth ones. Therefore, let us first analyze the processes that are observed in the area from the first to the fourth clusters.

First, let us consider a dendrogram obtained in conditions where there was no brain activation through automated motor activity (Fig. 3). Thus, after the perception of information (in our case, an ophthalmologic ring), the information enters the short-term memory (see the first cluster). At the same time (see the second cluster), the accuracy $\left(\boldsymbol{T}_{2}\right)$ is checked, i.e., the correspondence of the information perceived and kept in short-term memory to its verbal engram (in our case, an engram of the ophthalmologic ring being analyzed at a given time) kept in long-term memory $(\boldsymbol{L T M} \boldsymbol{W})$. The described processes occurring in the first and second clusters, in fact, affect the speed of work with the form sheet (parameters $\boldsymbol{Q}, \boldsymbol{A})$, and its productivity $(\boldsymbol{A y p})$. In other words, these processes determine and clarify what kind of information will go into working memory.

Now let's look at the processes occuring from the first to the fourth clusters during mastication of chewing gum (Fig. 4). Changes in the first cluster clearly demonstrate that in short-term memory, the engram of the perceived digit (or sign) is replaced by its verbal image. At the same time, the connection between $\boldsymbol{S T M} \boldsymbol{W}$ and $\boldsymbol{Q}$ parameters indicates that the described process is directly influenced by the speed of visual information processing. Such restructuring testifies to a faster and more accurate identification of the perceived information. Alongside this, the already described interaction between the parameters $\boldsymbol{T}_{2}$ and $\boldsymbol{L T M} \boldsymbol{W}$ takes place in the second cluster.

Next we should consider the third cluster (the parameters $\boldsymbol{A}$ and $\boldsymbol{A y \boldsymbol { y }}$ ). Let us remind that the parameter $\boldsymbol{A y p}$ is calculated according to the following formula (1):

$$
\boldsymbol{A y p}=\boldsymbol{A} \times \frac{M-(\boldsymbol{O}+\boldsymbol{P})}{n},
$$

where $\boldsymbol{A}$ is the proofreading speed, $\boldsymbol{M}$ is the total number of crossed out characters, $\boldsymbol{O}$ is the number of erroneously crossed out characters, $\boldsymbol{P}$ is the number of missed characters, and $\boldsymbol{n}$ is the number of characters to be crossed out. In other words, it includes both the speed of work and the degree of error-free operations performed [33; 35]. Thus, Ayp is, so to say, an integrative parameter that reflects all the described attention processes, and also points out that the speed of work is directly determined by the processes that occur in the first and second clusters.

As we remember, automated motor activity leads to a, though not reliable, but still decrease in the amount of working memory. This is probably due to the described restructuring in the hierarchy of information processing, as well as to the disappearance of a significant positive correlation with the attention parameter of "Mental productivity" $\left(\boldsymbol{E}_{2}\right)$ and to the emergence of a significant indirect relationship with short-term memory $($ STM_W $)$. 
Thus, we clearly see that the processes occurring from the first to the fourth clusters form a single block. This block illustrates, firstly, how the processing and selection of the information perceived at a given moment occurs, secondly, with what speed these processing and selection are carried out, and, thirdly, what information will be in the working memory.

The fifth and the sixth clusters in both dendrograms are identical (Fig. 3-4). Let us now look at them closer.

The fifth cluster is formed by the attention parameters $\boldsymbol{E}_{2}$ and $\boldsymbol{V}$. This cluster describes information processing that occur in parallel with those described above. In their essence, these parameters in the whole describe the processes that are associated both with the throughput of the information processing channel and with the mental efforts required to process it. Here we can see the interconnection of the information selection process and mental resources that allow a person to process this information. This relationship reconciles the selective models of D. Broadbent [39] and A. Treisman [40-42] with the resource model of D. Kahneman [43].

And finally, let us have a closer look at the attention parameters $\boldsymbol{K}$ and $\boldsymbol{R}$, which make up the last cluster, the sixth one. Here we can see that attention concentration and performance evaluation occur alongside with the information processing. Due to the rather high value of the linkage distance between the parameters $\boldsymbol{K}$ and $\boldsymbol{R}$, combining them into one cluster seems to us doubtful. Nevertheless, we can assume that the connection formed may be based on slightly different processes that may occur under the influence of certain personality traits or states of a testee. As can be seen from the correlation (Table 2) analysis, there is a close and significant relationship between the $\boldsymbol{K}$ and $\boldsymbol{R}$ parameters. This means that the parameters under consideration can describe completely different, but still related psychological phenomena. It is possible that such processes as attention concentration and performance evaluation belong to a higher level of information processing, where, along with the cognitive ones, the processes of volitional regulation of concentration on current activity are also involved.

The allocation in the dendrogram of the unit for information processing and selection, as well as its transfer into the working memory (the first-fourth clusters), on the one hand, and the fifth and sixth clusters, on the other, indirectly confirms D. Norman's assumption about the parallel processing of information, which he put forward back in 1968 [44]. In addition, the cluster model obtained in our study widens and specificates the concepts of selection and information processing proposed by O. Neumann [45] and A. Van der Heijden [46; 47].

\section{Conclusion}

Basing on the results of this research, we can state that mastication of chewing gum can significantly enhance attention and memory. This is manifested in the fact that there is a reliably significant improvement in the parameters of attention and short-term memory, as well as a tendency to improvement of long-term memory. However, against this background, there is also a negative tendency towards a deterioration in the working memory span.

Along with this, there happens a rearrangement of the structure of significant correlations and the hierarchy of stage-by-stage information processing, including information entering the working memory.

Taking into consideration the close connection of attention and memory with other cognitive processes, as well as our earlier data [34], we assume that involuntary motor activity can lead to predominantly positive changes in them.

It remains unclear what makes the main contribution to the described changes: the motor activity associated with chewing, the activation of digestive centers, or, possibly, the 
combination of these factors against the background of the attentive mindset. These issues require further psychophysiological research.

The prospect of further data analysis lies in their investigation in terms of sex differences as well as in complex with the data of testees' personality traits and other cognitive processes.

\section{References}

1. Th. Ribot, The psychology of attention, $5^{\text {th }}$ ed, (Open Court Publishing Co, Chicago, 1903)

2. I.P. Pavlov, Complete Works (AN SSSR, v. 4, Moscow-Leningrad, in Russian, 1951)

3. Y.B. Dormashev, V.Y. Romanov, Psychology of attention (Trivola Moscow, in Russian, 1995)

4. A. Pease, Body Language. How to read other's thoughts by their gestures (Sheldon press, London, 1997)

5. P. Ekman, Telling Lies: Clues to Deceit in the Marketplace, Politics, and Marriage (W.W. Norton \& Co, NY, 2009)

6. C. Sanchis, E. Blasco, F.G. Luna, J. Lupiáñez, Effects of caffeine intake and exercise intensity on executive and arousal vigilance, Scientific Reports, 10(1), 8393, doi: 10.1038/s41598-020-65197-5 (2020).

7. R. Desimone, J. Duncan, Neural mechanisms of selective visual attention, Annu Rev. Neurosci, 18, 193-222 (1995)

8. A.M. Ivanitskii, I.R. Il'yuchenok, G.A. Ivanitskii, Selective attention and memory: evoked potentials in visual and auditory verbal competition, Zhurnal vysshei nervnoi deiatelnosti im. I. P. Pavlova, 53(5), 541-551, in Russian (2003)

9. R. Naatanen, Attention and brain function (Erlbaum, Hillsdale-NJ, 1992)

10. M.V. Slavutskaya, Cortical mechanisms of attention and eye movements in humans (Doctor's degree in Biology, Moscow, in Russian, 2006)

11. E.N. Sokolov, Memory mechanisms (MGU Moscow, in Russian, 1969)

12. N.F. Suvorov, O.P. Tairov, Psychophysiological Mechanisms of Selective Attention (Nauka Leningrad, in Russian, 1985)

13. G.R. Mangun, A.P. Jha, J.B. Hopfinger, T.C. Handy, The temporal dynamics and functional architecture of attentional processes in human extrastrate cortex. The New Cognitive Neurosciences. A Bradford Book (The Mit Pess, Cambridge-MassachusetsLondon, 2000)

14. M.I. Posner, Comulative development of attentional theory, Amer. Psychol, 37(2), 168-180 (1982)

15. M.I. Posner, Orienting of attention Quarterly, Journal of Experimental Psychology, 32, 3-25 (1980)

16. B.G. Anan'ev, Education of the schoolchildren's attention (APN RSFSR, MoscowLeningrad, in Russian, 1946)

17. N.F. Dobrynin, Attention and memory (Znanie, Moscow, in Russian, 1958)

18. P.B. Nevel'skii, Memory, attention and information, Tezisy doklada na II s"ezde Obshchestva psikhologov, 1, 38-39 (APN, RSFSR, Moscow, in Russian, 1963)

19. A.P. Nechaev, Psychology essay for educators and teachers (Prosveshchenie, Moscow, in Russian, 1993) 
20. N.V. Serkova, Peculiarities of the dynamics of attention and mental rigidity development of students in distance and traditional education (Candidate's Degree in Psychology, in Russian, Tomsk, 2000)

21. A.P. Bizyuk, Foundations of neuropsychology (Rech', in Russian, Saint Petersburg, 2010)

22. Pavlov's Wednesdays. Protocols and transcripts of physiological conversations, v. 2 (AN SSSR, Moscow, Leningrad, in Russian 1949)

23. B.G. Anan'ev, Selected psychological works, v. 1 (Pedagogika, Moscow, in Russian, 1980)

24. G.M. Whipple, Manual of mental and physical tests, Part 1, 263-348 (Warwick and York, inc., Baltimore, U.S.A., 1910)

25. R.E. Franken, Human Motivation. $6^{\text {th }}$ ed. (Thomson/Wadsworth, Australia-Belmont, CA, 2007)

26. C. Sperman, The abilities of man. Their nature and measurement, Chap. 15 (Macmillan and Co, London, 1927)

27. F.N. Gonobolin, Attention and its education (Pedagogyka, in Russian, Moscow, 1972)

28. L.P. Grigor'eva, Formation of attention mechanisms in sensory-perceptual deficit, Part 2 Defektologiya, 3-17 (in Russian, 2003)

29. L.P. Grigor'eva, Psychophysiology of attention development in normal children and in children with complex sensory impairments, Part 1 Defektologiya, 3-14 (in Russian, 2002)

30. N.N. Lange, Psychological research. The law of perception. Voluntary attention theory (Psikhologicheskoe obshchestvo, in Russian, Odessa, 1893)

31. I.A. Moskalik, Dynamic pattern of attention in deaf schoolchildren in the process of visual perception (Candidate's Degree in Psychology, in Russian, Saint-Petersburg, 2005)

32. I.M. Sechenov, Selected works: physiology and psychology, v. 1 (AN SSSR, Moscow, in Russian, 1952)

33. E.Yu. Brunner, Better than super attention: methods of diagnostics and psychocorrection (Feniks, Rostov-na-Donu, in Russian, 2006)

34. E. Yu. Brunner, Characteristic features of attention and memory in young male opiatedependents, Problemy sovremennogo pedagogicheskogo obrazovaniya, 48 (1), 372399 (2015)

35. E.Yu. Brunner, New opportunities for the attention diagnostics with the help of a proofreading test based on E. Landolt's ophthalmological rings, Problemy sovremennogo pedagogicheskogo obrazovaniya, 48 (1), 364-3723 (2015)

36. A. A. Ukhtomskii, Collected Works (v. 1, LGU, Leningrad, in Russian, 1950)

37. M.L. Sedokova, L.F. Kazionova, T.A. Tomova, Age anatomy and physiology (Tomskiy gosudarstvennyy pedagogicheskiy un-t (TGPU), Tomsk, in Russian, 2009)

38. E. Brunner, Peculiarities of Attention Parameters and their Dynamics in 17-23-YearOld Female Students, Psychological service of higher education institutions, 79-100 (Nova Science Publishers, New York, 2020)

39. D.E. Broadbent, Decision and Stress (Academic Press, London, 1971)

40. A. M. Treisman, Selective attention in man, British Medical Bulletin, 20, 12-16 (1964)

41. A.M. Treisman, Strategies and models of selective attention, Psychological Review, 76, 282-299 (1969) 
42. A.M. Treisman, Monitoring and storage of irrelevant messages in selective attention, J. of Verbal Learning and Verbal Behavior, 3, 449-459 (1964)

43. D. Kahneman, Attention and effort (Prentice Hall, N. J., 1973)

44. D. Norman, Toward a theory of memory and attention, Psychological Review, 75. 522$536(1968)$

45. O. Neumann, Visual attention and action, In O. Neumann \& W. Prinz (Eds.), Relationships Between Perception and Action: Current Approaches, 227-267 (1990)

46. A.H.C. Van der Heijden, Attention in vision: Perception, communication and action (Psychology Press, Hove-New York, 2004)

47. A.H.C. Van der Heijden, Selective attention in vision (Routledge, London-New York, 1992) 